\title{
A gas chromatography-mass spectrometry untargeted metabolomics approach to discriminate Fiore Sardo cheese produced from raw or thermized ovine milk
}

\author{
P. Caboni, ${ }^{1 *}$ D. Maxia, ${ }^{1,2}$ P. Scano,,${ }^{3,4}$ M. Addis, ${ }^{5}$ A. Dedola, ${ }^{5}$ M. Pes, ${ }^{5}$ A. Murgia, ${ }^{6}$ M. Casula, ${ }^{1}$ A. Profumo, ${ }^{2}$ \\ and A. Pirisi ${ }^{5}$ \\ ${ }^{1}$ Department of Life and Environmental Sciences, University of Cagliari, via Ospedale 72, 09124 Cagliari, Italy \\ ${ }^{2}$ Department of Chemistry, University of Pavia, viale Taramelli 12, 27100 Pavia, Italy \\ ${ }^{3}$ Department of Chemical and Geological Sciences, University of Cagliari, SS 554 km 4.5, 09042 Monserrato, Cagliari, Italy \\ ${ }^{4}$ Institute for Macromolecular Studies (CNR-ISMAC), Via Corti 12, 20133 Milano, Italy \\ ${ }^{5}$ Agris Sardegna, Servizio Ricerca Prodotti di Origine Animale, Loc. Bonassai, 07040 Olmedo, Italy \\ ${ }^{6}$ Department of Biochemistry and Cambridge Systems Biology Centre, University of Cambridge, 80 Tennis Court Road, Cambridge, CB2 1GA, \\ United Kingdom
}

\section{ABSTRACT}

Thermization is a sub-pasteurization heat treatment of cheese milk (at $57-68^{\circ} \mathrm{C}$ for $15-30 \mathrm{~s}$ ) aimed to reduce the number of undesirable microbial contaminants with reduced heat damage to the indigenous milk enzymes. In this work, the effects of milk thermization on the compositional parameters, proteolysis indices, free fatty acid levels, and low molecular weight metabolite profiles of ovine cheese were studied. Cheese samples at different ripening stages and produced in 2 different periods of the year were analyzed. While the effects of milk thermization on cheese macro-compositional parameters and free fatty acid levels were not evident due to the predominant effects of milk seasonality and cheese ripening stage, the gas chromatography-mass spectrometry based metabolomics approach of ovine cheese produced from raw and thermized milk highlighted strong differences at the metabolite level. Discriminant analysis applied to gas chromatography-mass spectrometry data provided an excellent classification model where cheese samples were correctly classified as produced from raw or thermized milk. The metabolites that mostly changed due to the thermization process belonged to the classes of free amino acids and saccharides. Gas chromatography-mass spectrometry-based metabolomics has proven to be a valid tool to study the effect of mild heat treatments on the polar metabolite profile in ovine cheese.

Key words: Fiore Sardo, heat treatment, ewe milk, partial least squares-discriminant analysis

Received October 19, 2018.

Accepted February 25, 2019.

*Corresponding author: caboni@unica.it

\section{INTRODUCTION}

Sardinia (Italy) plays a relevant role in European Union sheep milk production of which $70 \%$ is transformed into 3 Protected Designation of Origin (PDO) cheeses: Pecorino Romano, Pecorino Sardo, and Fiore Sardo. According to the PDO specification, beyond intrinsic technological aspects, these cheeses differ in the milk heat treatments. In particular, Fiore Sardo cheese must be produced with raw ovine milk, whereas for Pecorino Romano and Pecorino Sardo cheese, heat treatment of milk is allowed. In European Union ovine cheese production, raw milk is used for several PDO cheeses such as Fiore Sardo and Pecorino di Filiano (Italy), Ossau-Iraty and Roquefort (France), and Roncal and Idiazabal (Spain).

In the dairy industry, milk is generally thermally treated to reduce the levels of viruses, bacteria, molds, yeasts, and protozoa. Common heat treatments are in order of increasing severity: thermization, pasteurization, extended shelf life treatment, UHT treatment, and in container sterilization. (Hilton and Lewis, 2017). These treatments have been shown to modify milk characteristics such as microbiota, carbohydrates, proteins, and lipids but also the enzymatic activity, renneting attitude, and the nutritional and sensory properties of dairy products (Vélez et al., 2010; Piga et al., 2013; Gathercole et al., 2017).

In the cheese industry, the thermal treatment of milk is a common practice. Generally, thermization and pasteurization are used to reduce undesirable microflora and pathogens and to lessen cheese technological defects. Usually, for semi-hard and hard ovine cheese production milk thermization is used. Few studies are available on the influence of thermization on ovine cheese characteristics. Though, milk thermization treat- 
ments may have negative effects on desirable lactic acid bacteria $(\mathbf{L A B})$ and on the biodiversity of the natural microflora of milk, and by inactivating thermolabile enzymes, it can also introduce numerous changes to milk components (Gaya et al., 2005; Raynal-Ljutovac et al., 2007). For example, in Greek hard cheese, the thermization process inactivated potentially protective LAB strains and enhanced the capability of potentially pathogenic enterococci to grow in the fresh cheese curds (Gaya et al., 2005). Microstructural differences were observed when comparing Pecorino cheese produced from raw or thermized milk (Mulas et al., 2013). Similarly, in PDO Fiore Sardo cheese, Pirisi et al. (1999) reported a greater calcium content and a more elastic cohesive texture in cheese produced from raw milk when compared with thermized milk. Currently, European Council regulations [EC Regulation 853/2004 (EC, 2004); EEC Directive 92/46 (EEC, 1992)] indicate the alkaline phosphatase test as an official method to detect milk heat treatments. The usefulness and reliability of this enzymatic test is a matter of debate (Scintu et al., 2000; Rankin et al., 2010) because of the false positives due to a possible reactivation of the enzyme in periods following the thermal treatment (Lyster and Aschaffenburg, 1962; Murthy et al., 1976; Farkye and Imafidon, 1995).

To the best of our knowledge, no official analytical methods or biomarkers able to discriminate between cheese obtained from raw or thermized milk are available at the moment. This is particularly important for PDO ovine cheeses as Fiore Sardo where the use of raw milk is mandatory and when fraudulent milk thermization procedures could be implemented.

Metabolomics is one of the -omic sciences for studying the pool of metabolites (metabolite profile) in a set of biological samples using high-throughput analytical platforms together with multivariate statistical tools that can be easily applied to dairy products (Afshari et al., 2018). Food metabolites include AA, nucleic acids, carbohydrates, organic acids, vitamins, polyphenols, inorganic species, and other components with nutritional properties. Applied to the characterization of milk and dairy products, GC-MS-based metabolomics has proven to be a robust approach thanks to its high sensitivity and ability to snap-shot a wide range of metabolites within a single analysis (Gowda and Djukovic, 2014). Our research group has conducted several studies on milk and dairy products with this approach and has found associations between metabolite profile and macroscopic data (Scano et al., 2014; Caboni et al., 2016; Pisano et al., 2016).

The aim of this work was to investigate, using a metabolomics approach, the modifications of the metabolite profile in ovine cheese caused by a milk ther- mization process and to assess whether the metabolite profile can be used as a biomarker for milk thermization in ovine cheese. To this goal, the hydrophilic low-molecular weight metabolites, detected by GC-MS, were studied in ovine cheese samples obtained from either raw or thermized milk. Milk collection and cheese manufacturing were performed in different periods of the year to reduce seasonal variability.

\section{MATERIALS AND METHODS}

\section{Chemicals and Reagents}

All chemicals were of analytical grade. Methanol, chloroform, hexane, trichloroacetic acid, pyridine, O-methylhydroxylamine hydrochloride, $N$-methyl- $N$ (trimethylsilyl)trifluoroacetamide, potassium chloride, phosphotungstic acid hydrate, and 2,2,3,3- $\mathrm{D}_{4}$-succinic acid were purchased from Sigma-Aldrich (Milano, Italy). Bi-distilled water was obtained with a MilliQ purification system (Millipore, Milan, Italy).

\section{Cheese Production and Sampling}

Bulk milk samples from mature Sarda ewes were collected in December 2016, and February, April, and May 2017, leading to 8 cheesemaking trials (I, II, III, and IV, for raw and heated milk, respectively) from the experimental farm of Agris Sardegna and processed into Fiore Sardo cheese type following the process reported in Figure 1. Each time, $120 \mathrm{~kg}$ of sheep raw bulk milk was split in 2 aliquots: $60 \mathrm{~kg}$ of raw milk (RM) and $60 \mathrm{~kg}$ of thermized milk (HM). Thermal treatment occurred in a batch-wise process by using an infrared tubular exchanger (model Stoutz-Actinator, ACTINI Group, Evian-les-Bains, France), in which milk was heated at $68^{\circ} \mathrm{C}$ for $30 \mathrm{~s}$ and quickly cooled down to $38^{\circ} \mathrm{C}$. The process was repeated under the same conditions to obtain 4 replicates for each milk treatment in the pilot plant of Agris Sardegna. To eliminate the effects of vat and cheesemaker, 2 vats of cheese, 1 with RM and 1 with HM alternately, were simultaneously used and the dairyman was the same for all cheesemaking. Six cheeses samples of approximately 1.5 to $1.7 \mathrm{~kg}$ were produced in each process, for a total of 24 raw milk cheeses (RC) and 24 heated milk cheeses (HC). For each production, 3 cheese loaves were sampled at 105 and $180 \mathrm{~d}$ of ripening, respectively.

\section{Milk and Cheese Composition, Nitrogen Fractions, and Free Fatty Acid Levels}

Samples of raw and thermized milk were analyzed for fat, proteins, casein, lactose content, and SCC using a 


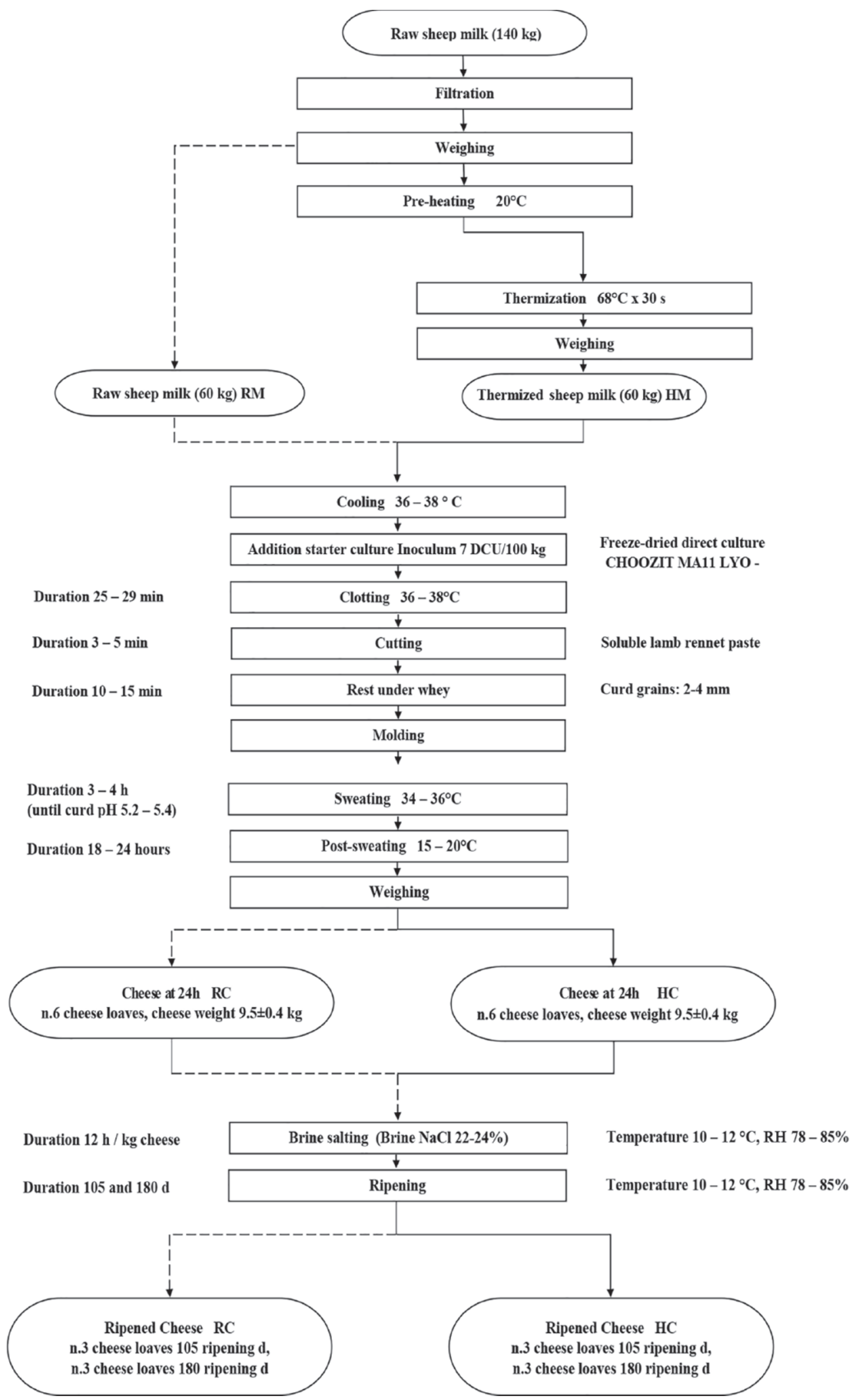

Figure 1. Fiore Sardo cheese production flowchart. $\mathrm{RC}=$ cheese from raw milk; $\mathrm{HC}=$ cheese from thermized milk; $\mathrm{HM}=$ thermized milk; $\mathrm{RM}=$ raw milk; $\mathrm{RH}=$ relative humidity; DCU = direct culture unit. Choozit MA11 LYO 50 DCU manufactured by Danisco (Copenhagen, Denmark). 
Combifoss FT+ (Foss, Hillerød, Denmark), pH using a Crison Basic 20+ pH meter (Crison Instruments S.A., Alella, Spain), and TS (ISO 6731; ISO, 2010). Cheese samples at 105 and $180 \mathrm{~d}$ of ripening were analyzed for pH, DM (ISO 5534; ISO, 2004), fat (Soxhlet, 1879), total nitrogen (TN; ISO 8968-1; ISO, 2014), soluble nitrogen at $\mathrm{pH} 4.6$, soluble nitrogen in $12 \%$ trichloroacetic acid (SN-TCA), and soluble nitrogen in 10\% phosphotungstic acid (SN-PTA; Gripon et al., 1975). Sodium chloride was determined by potentiometric titration with $\mathrm{AgNO}_{3}$ (ISO 5943; ISO, 2006; automatic titrator Mettler-Toledo DL55, Mettler-Toledo GmbH, Schwerzenbach, Switzerland). Protein content in cheese was calculated as follows: protein $=[(\mathrm{TN}) \times 6.38]$.

Cheese free fatty acid (FFA) levels were determined as previously described by Addis et al. (2005).

\section{Sample Preparation for GC-MS}

Milk and shredded cheese samples were stored into sterile plastic Falcon tubes at $-20^{\circ} \mathrm{C}$ before analysis. Milk and cheese samples were thawed on ice. Milk samples were sonicated for $15 \mathrm{~min}$ and an aliquot of $100 \mu \mathrm{L}$ was poured in a 1.5-mL Eppendorf tube. Finely shredded cheese samples were weighed $(50 \mathrm{mg})$ and transferred into sterile tubes. To each milk sample, $250 \mu \mathrm{L}$ of methanol and $125 \mu \mathrm{L}$ of chloroform were added (Caboni et al., 2016). Samples were sonicated for $15 \mathrm{~min}$, and $380 \mu \mathrm{L}$ of chloroform and $90 \mu \mathrm{L}$ of aqueous $\mathrm{KCl} 0.2 M$ were added and finally vortexed for $10 \mathrm{~s}$. Samples were then centrifuged at $15,294 \times g$ for $10 \mathrm{~min}$ at $4^{\circ} \mathrm{C}$ (Eppendorf 5810R, Milan, Italy). A volume of $200 \mu \mathrm{L}$ of both aqueous and organic layer was extracted from each sample and moved into different 1.5 sterile glass vials and dried under a gentle nitrogen stream. The aqueous layer was derivatized first using $50 \mu \mathrm{L}$ of methoxyamine hydrochloride dissolved in pyridine at $10 \mathrm{mg} / \mathrm{mL}$, homogenized for $20 \mathrm{~s}$, and kept at room temperature for $17 \mathrm{~h}$. Then, $100 \mu \mathrm{L}$ of $\mathrm{N}$-methyl- $\mathrm{N}$-(trimethylsilyl)trifluoroacetamide was added and samples were vortexed. After $1 \mathrm{~h}, 600 \mu \mathrm{L}$ of hexane containing $5 \mathrm{mg} / \mathrm{L}$ of $2,2,3,3-\mathrm{D}_{4}$-succinic acid was added as the internal standard and homogenized again before GC-MS analysis. Cheese samples were treated with $200 \mu \mathrm{L}$ of methanol, $250 \mu \mathrm{L}$ of chloroform, and $10 \mu \mathrm{L}$ of $1 \%$ aqueous trichloroacetic acid. Samples were vortexed 4 times for $15 \mathrm{~s}$ every $15 \mathrm{~min}$. Then, $760 \mu \mathrm{L}$ of chloroform and $90 \mu \mathrm{L}$ of aqueous $\mathrm{KCl} 0.2 \mathrm{M}$ were added and vortexed for $10 \mathrm{~s}$. Samples were then centrifuged at $15,294 \times g$ for $10 \mathrm{~min}$ at $4^{\circ} \mathrm{C}$. A volume of $100 \mu \mathrm{L}$ of the aqueous phase was evaporated under a nitrogen stream and derivatized as previously described (Caboni et al., 2016).

\section{GC-MS Analysis}

The derivatized samples were analyzed with a Hewlett Packard 6850 Gas Chromatograph, 5973 mass selective detector, and 7683B series injector (Agilent Technologies, Palo Alto, CA), using helium as the carrier gas at $1.0 \mathrm{~mL} \cdot \mathrm{min}^{-1}$ flow. One microliter of sample was injected in the split-less mode and resolved on a $30 \mathrm{~m} \times 0.25 \mathrm{~mm} \times 0.25 \mu \mathrm{m}$ DB-5MS column (Agilent Technologies). Inlet, interface, and ion source temperatures were 250,250 , and $230^{\circ} \mathrm{C}$, respectively. Oven starting temperature was set to $50^{\circ} \mathrm{C}$, final temperature to $230^{\circ} \mathrm{C}$ with a heating rate of $5^{\circ} \mathrm{C} \mathrm{min}^{-1}$ for $36 \mathrm{~min}$ and then for 2 min at constant temperature. Electron impact mass spectra were recorded from $\mathrm{m} / z$ 50 to 550 at $70 \mathrm{eV}$. The resulting data were analyzed using MSD ChemStation software (Agilent Technologies). The identification of metabolites was performed by comparison with instrumental analytical standards injected database and by metabolite mass spectra comparison with the NIST14 library of the National Institute of Standards and Technology (Gaithersburg, MD). The GC-MS spectra deconvolution was performed through NIST14 library's AMDIS tool. For each metabolite, the GC-MS peak area related to the most abundant and representative mass fragment was calculated using MSD ChemStation software.

\section{Statistical Data Analysis}

Physico-chemical and FFA data of cheeses were analyzed with the statistical package Minitab 16 (Minitab 16 Statistical Software, 2010, Minitab Inc., State College, PA). General linear model analysis was used to verify the effects of the thermization (F, 2 levels) and the effect of period (F, 4 levels). The comparison between means was performed using Tukey's significant difference test $(P<0.05)$. After GC-MS analysis of milk samples, a $8 \times 71$ data matrix was obtained. For each sample the total sum of metabolites area was calculated. Matrix was then normalized row wise by dividing each metabolite's area for the corresponding sum value. The same procedure was applied for the $48 \times 64$ cheese data matrix. Multivariate statistical analysis of GC-MS data was performed as implemented in SIMCA-P+ software (version 14.1, Umetrics, Umeå, Sweden). Prior to multivariate statistical analysis, variables (metabolites) were mean centered and scaled to unit variance column wise, and row-wise normalization adopted. Principal component analysis was performed to investigate sample distributions, deviating features and common trends. The partial least squares-discriminant analysis and its orthogonal variant (OPLS-DA) were performed for 
classification of samples and identification of the most discriminant variables. Classificatory and predictive powers were verified based on the goodness of fit $\left(\mathbf{R}^{2} \mathbf{Y}\right)$ and goodness of prediction, determined through cross validation $\left(\mathbf{Q}^{2} \mathbf{Y}\right)$. Models were tested for overfitting by permutation tests $(\mathrm{n}=400)$, and negative values of the obtained intercept $\left(\mathrm{Q}_{\text {intercept }}^{2}\right)$ indicate more robust models. The variable importance in projection (VIP) score summarizes the contribution of each variable to the model. The VIP scores in the predictive component were analyzed and only those metabolites having VIP values $>1$ were considered as discriminant between the classes (Eriksson et al., 2006).

\section{RESULTS AND DISCUSSION}

\section{Milk Composition Analysis}

Milk composition data of RM and HM are reported in Supplemental Table S1 (https://doi.org/10.3168/jds .2018-15885). Fat and protein levels follow the normal seasonal variation observed for Sardinian sheep milk (Carta et al., 1995). Fat content displayed a minimum on February and increased in the following months, in comparison the protein content showed a slower increase from December to May as expressed by the fat to protein ratio. The SCC were found to be higher in January and February. The thermization treatment did not affect the milk composition in any of the considered production periods.

\section{Cheese Macro Composition Analysis and Proteolysis Indices}

In Tables 1 and 2 we reported the physico-chemical composition and proteolysis indices (SN/TN, SN-TCA/ TN, and SN-PTA/TN) for cheeses, at 105 and $180 \mathrm{~d}$ of ripening. In cheese at $105 \mathrm{~d}$ of ripening (Table 1), the milk thermization treatment did not affect the $\mathrm{pH}$ value, moisture, fat, and protein content in any considered production period. Regardless of the heat treatment of cheese milk, the production period affected the $\mathrm{pH}$ and the main macro-composition. Cheeses produced in February and May reached, after 105 d of ripening, a $\mathrm{pH}$ value significantly higher than those produced in December and April. The cheeses produced in February were characterized by a higher moisture content compared with those produced in April and May $(P<$ 0.01, Table 1). Moreover, the cheese fat content reflects the trend of fat and the fat/protein ratio in the milk, decreasing significantly from December to February and increasing from February to May $(P<0.001)$, and the protein content increasing significantly from

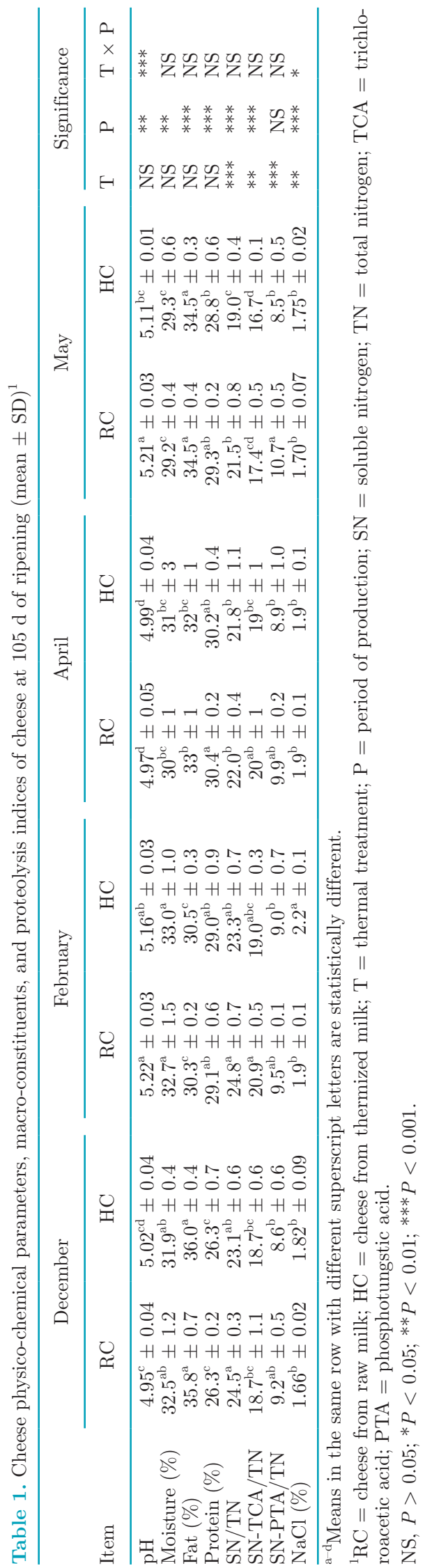

Journal of Dairy Science Vol. 102 No. 6, 2019 


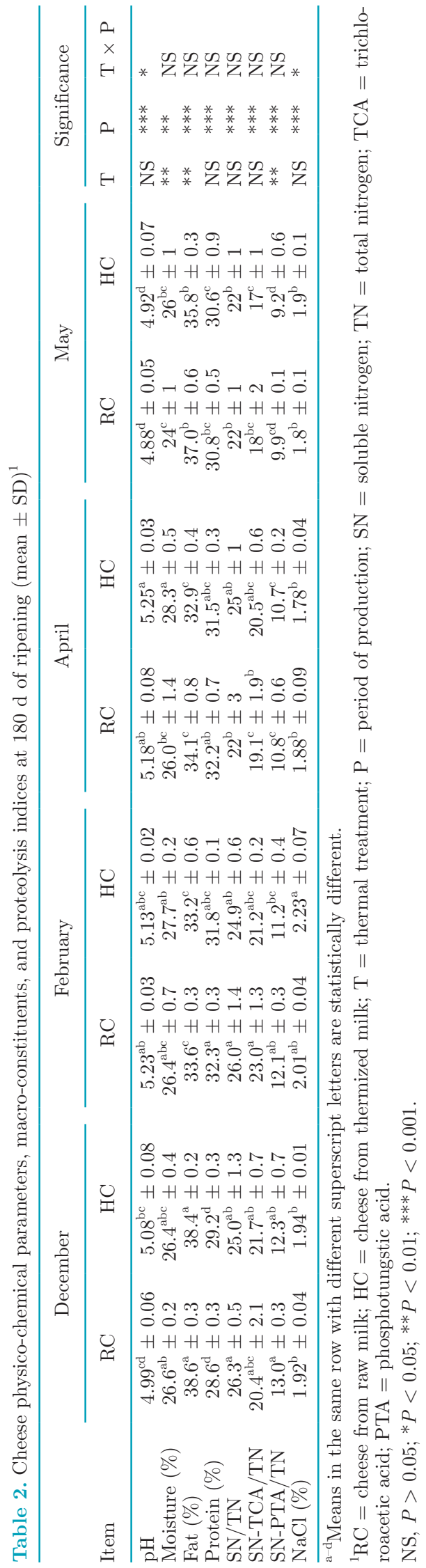

December to February remaining almost unchanged in the following months.

The values shown in Table 1 reflect, in general, a weak proteolytic ripening, characteristic of this type of cheese and comparable to what was reported by Pirisi et al. (1999). Contrary to what was observed by these authors, who did not find significant differences in the proteolysis indices of Fiore Sardo produced from raw or thermized milk, we observed, in general, a more pronounced proteolysis in $\mathrm{RC}$ compared with $\mathrm{HC}$ cheese at $105 \mathrm{~d}$ of ripening. This trend was significant for the $\mathrm{SN} / \mathrm{TN}(21.5$ vs. $19.0 ; P<0.001)$ and SN-PTA/TN (10.7 vs. $8.5 ; P<0.001)$ ratios in cheese produced in May. The heat treatment on milk, besides reducing the bacterial load, may have induced a partial denaturation of the enzymes responsible for the proteolysis of cheese, in particular, bacterial peptidases, mainly produced by the microorganisms of the native milk microflora, which are responsible for secondary proteolysis and therefore for the development of the SN-PTA fraction. In cheese at $105 \mathrm{~d}$ of ripening, a positive correlation was found between cheese moisture, $\mathrm{SN} / \mathrm{TN}\left(\mathrm{R}^{2}=\right.$ $0.76 ; P<0.001)$ and SN-TCA $/ \mathrm{TN}\left(\mathrm{R}^{2}=0.60 ; P<\right.$ 0.01 ). Moisture, ensuring a greater water activity, was able to favor the enzymatic degradation of proteins. No correlation between proteolysis and $\mathrm{NaCl}$ content was found. The highest $\mathrm{NaCl}$ content was found for $\mathrm{HC}$ produced in February, the highest moisture content of cheese produced in February may have also favored a better dissolution and permeation of sodium chloride.

In 180-d ripened cheeses, excluding samples produced in December, HC showed a higher moisture content when compared with $\mathrm{RC}$ and this difference was statistically significant for the samples produced in April $(P<0.01$, Table 2$)$. A possible explanation is that the milk heat treatment promotes the interactions between caseins and the whey proteins. The latter has a marked ability to retain the water that is then incorporated into the protein matrix, thus conferring greater moisture to the cheese.

Due to natural water evaporation, samples at 180 d compared with those at $105 \mathrm{~d}$ showed a decrease in moisture content with subsequent higher levels of fat and proteins. In fact, for RC samples, from 105 to 180 $\mathrm{d}$, the loss of moisture, as well as the concentration of fat and proteins, was significant for all the periods of production considered, whereas for $\mathrm{HC}$ samples it was significant only for the months of December and February.

In general, an increase of the proteolytic indices is observed during cheese ripening (Santiago-López et al. 2018). In RC samples, when 105-d samples are compared with $180 \mathrm{~d}$, the increase of the SN-PTA/TN value was statistically significant $(P<0.01)$ in the cheese 
produced in December and February. In HC samples, the increase of the proteolytic indices was always statistical significant, except for the $\mathrm{SN} / \mathrm{TN}$ ratio in the cheese produced in December and February and for the $\mathrm{SN}-\mathrm{TCA} / \mathrm{TN}$ and SN-PTA/TN ratios for the cheese produced in May.

\section{Cheese FFA Profiles}

During cheese ripening, the progress of lipolysis and FFA catabolism are the main factors responsible for the flavor development (Collins et al., 2003). In Tables 3 and 4 we reported the levels of FFA determined in the RC and $\mathrm{HC}$ samples at 105 and $180 \mathrm{~d}$ of ripening, respectively. The FFA were grouped into 3 main groups based on the chain length of carbon atoms: short-chain (C4:0, C6:0, C8:0, and C10:0), medium-chain (C12:0, $\mathrm{C} 14: 0$, and $\mathrm{C} 16: 0)$, and long-chain (C18:0, C18:1, C18:2, and C18:3) fatty acids. At $105 \mathrm{~d}$, thermization had statistically significant effects only on short-chain FFA, whereas at $180 \mathrm{~d}$ all the FFA levels were affected by the heat treatment. When compared with the HC, the $\mathrm{RC}$ samples at $105 \mathrm{~d}$ of ripening showed an overall higher content of the short-chain FFA. Similar results were found by Pinna et al. (1999) on Fiore Sardo cheese samples obtained from raw and thermized at $65^{\circ} \mathrm{C}$ milk. This fact can be explained by a partial inactivation of the endogenous lipoprotein lipase (LPL) due to the thermization milk treatment (Driessen, 1989; Sousa and Malcata, 1997). As highlighted by $\mathrm{Ha}$ and Lindsay (1993), the native milk lipase is characterized by a certain selectivity for the $s n-1$ and $s n-3$ positions of the triglycerides where the short-chain fatty acids, predominantly $\mathrm{C} 4: 0$ and $\mathrm{C} 6: 0$, are esterified. At 105 $\mathrm{d}$ of ripening, the medium- and long-chain fatty acid contents were not significantly different between RC and $\mathrm{HC}$, which could be explained by hypothesizing a selectivity of LPL to the $s n-1$ and $s n-3$ positions of triglycerides and to the fatty acid chain length. In fact, the latter fatty acid can exert a steric hindrance to the enzyme's activity on the triglyceride.

After $180 \mathrm{~d}$ of ripening (Table 4), RC cheeses are characterized by a significantly higher lipolysis when compared with $\mathrm{HC}$ cheeses and the differences were statistically significant for all FFA.

Except for samples produced in December, as ripening progresses, these differences in the FFA content between RC and HC are emphasized. In fact, in 180-d ripened cheeses not only short-chain fatty acids but also the medium- and long-chain fatty acids are higher in $\mathrm{RC}$ than in $\mathrm{HC}$ cheeses. Probably, after a first phase of the lipolysis process, in which the external and sterically less encumbered position of the triglyceride (the $s n-3)$ was preferentially hydrolyzed, the LPL, with the

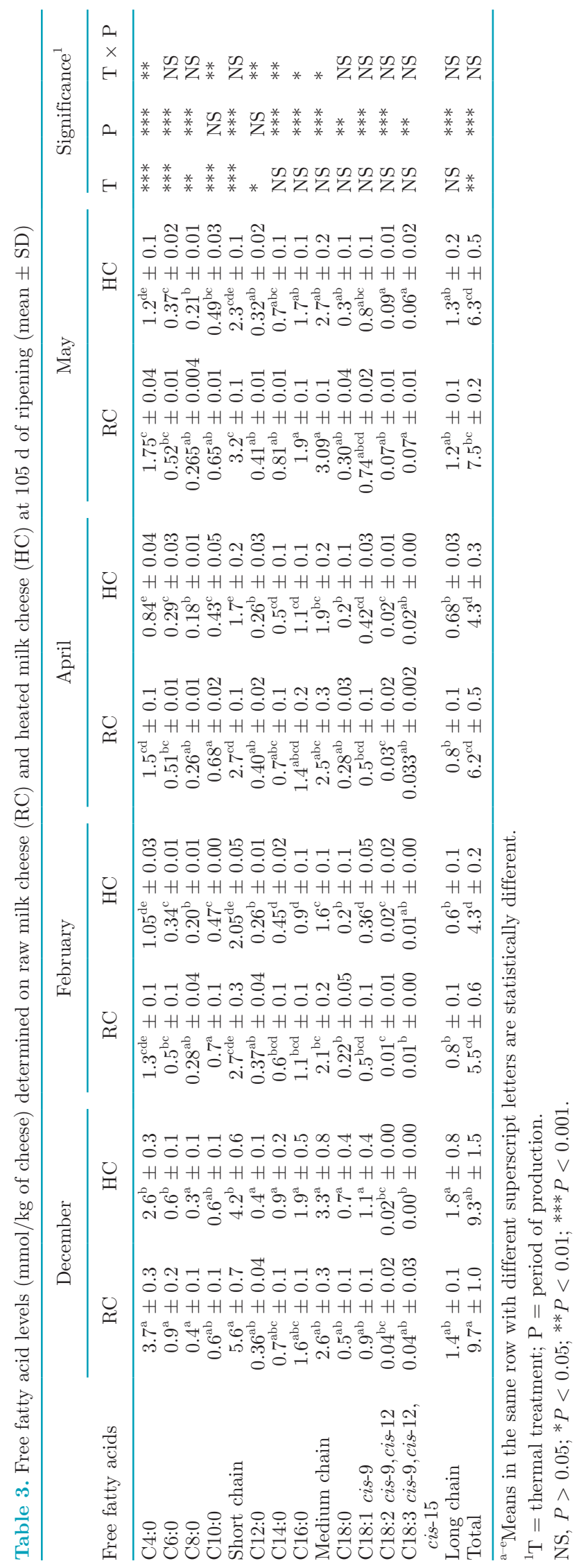

Journal of Dairy Science Vol. 102 No. 6, 2019 


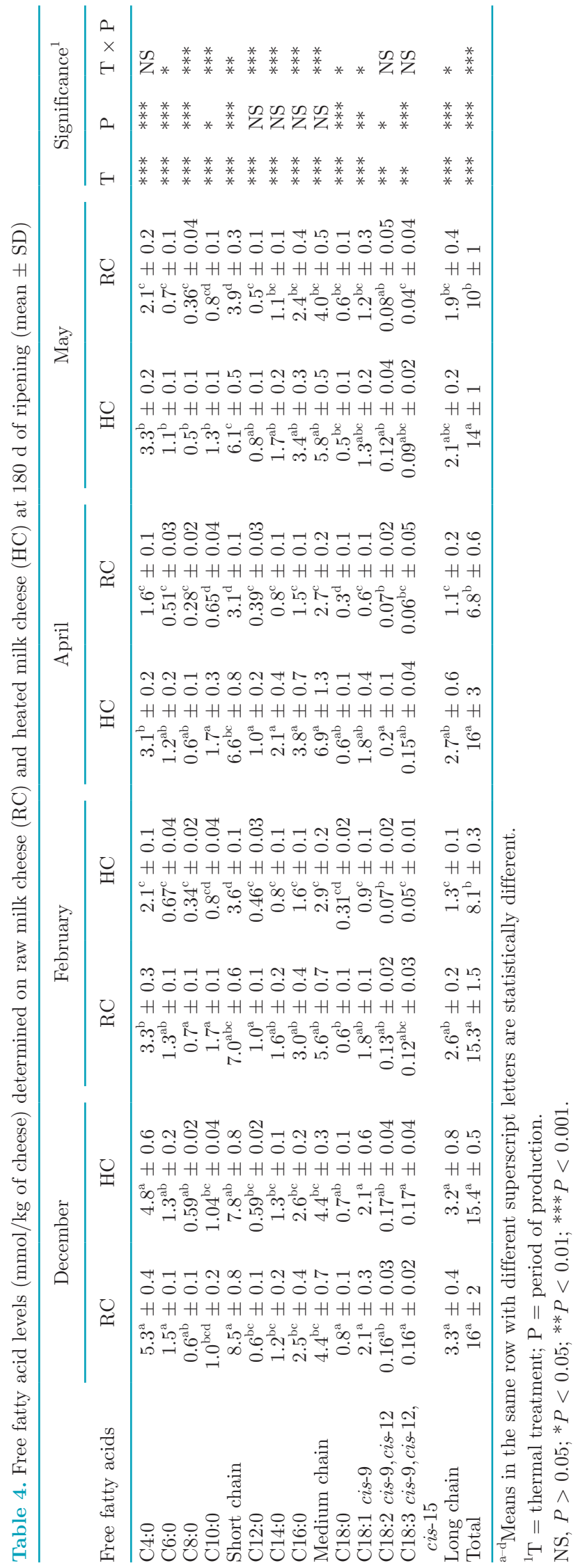

ripening progress, was able to hydrolyze also the less accessible sites ( $s n-2$ and $s n-1)$ where the medium- and long-chain fatty acids are preferentially esterified.

At $105 \mathrm{~d}$ of ripening, the month of production had a significant effect on the FFA content on both RC and $\mathrm{HC}$ samples. A greater lipolysis was observed in the cheese produced in the month of December, followed by those produced in May, April, and February, and following the same trend as the fat content. This observation is supported by the strong correlation with these parameters $\left(\mathrm{R}^{2}=0.85, P<0.001\right)$.

At 180 d compared with 105 d, we observed a generally and statistically significant increase of FFA $(P<$ 0.001) for both RC and HC samples, except for the C18:0 levels in the HC samples. This fact is probably due to the cheese-making technology, which involves the use of lamb paste rennet, which contains lipolytic enzymes of both pregastric and gastric origin that catalyzed the hydrolysis of triglycerides. Overall, differences in the FFA profile between the $\mathrm{HC}$ and $\mathrm{RC}$ samples, especially in the short-chain fatty acids, can lead to different flavor development.

\section{GC-MS Metabolomics}

Representative chromatograms of RC and HM samples at 105 and $180 \mathrm{~d}$ of ripening are shown in Figure 2. Table 5 shows the metabolites identified in cheese samples (i.e., AA, hydroxylated short-chain fatty acids, polyols, and mono- and disaccharides). With respect to the original milk, cheese samples showed a different profile of AA, hydroxylated short-chain fatty acids, and sugars. From the mass spectra analysis of each chromatographic peak we were able to annotate 82 metabolites, whereas 30 were considered unknowns.

Principal component analysis was first carried out on GC-MS cheese data. Two strong outliers (samples HC11180 and RC33180) were found and therefore excluded from the statistical analysis. Therefore, a pairwise OPLS-DA "RC vs. HC" was carried out on 46 samples, and results indicated a good fitting and an excellent classification power $\left(R^{2} Y=0.98, Q^{2} Y=0.90\right.$, classification 100\%). The score plot is shown in Figure 3 and the most discriminant metabolites obtained from the analysis of the VIP values are reported in Table 6 . Significant changes in cheese carbohydrates were observed with galactose as the most upregulated metabolite when HC samples were compared with RC samples. This observation agrees with previous studies by Olano and Calvo (1989) and Troyano et al. (1996) that reported the formation kinetics of galactose and tagatose during the heating of milk at various temperatures. Another upregulated annotated metabolite was gluconic acid, a weak organic acid found in dairy products po- 
RC 105

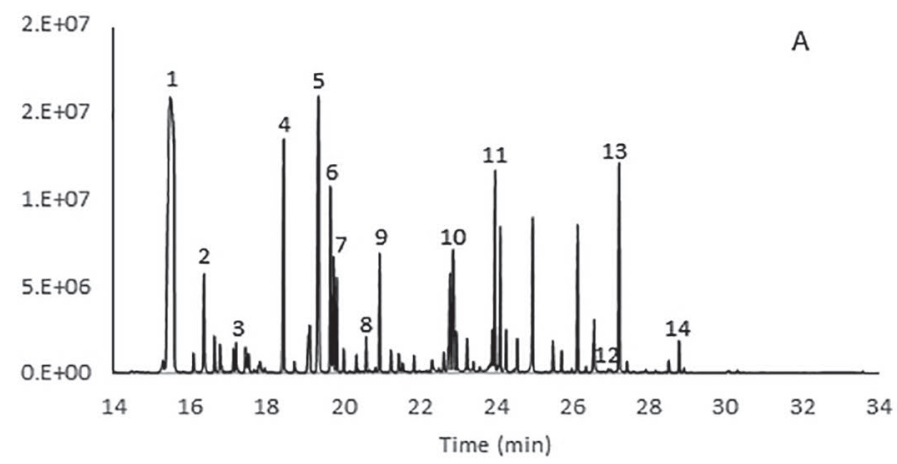

HC 105

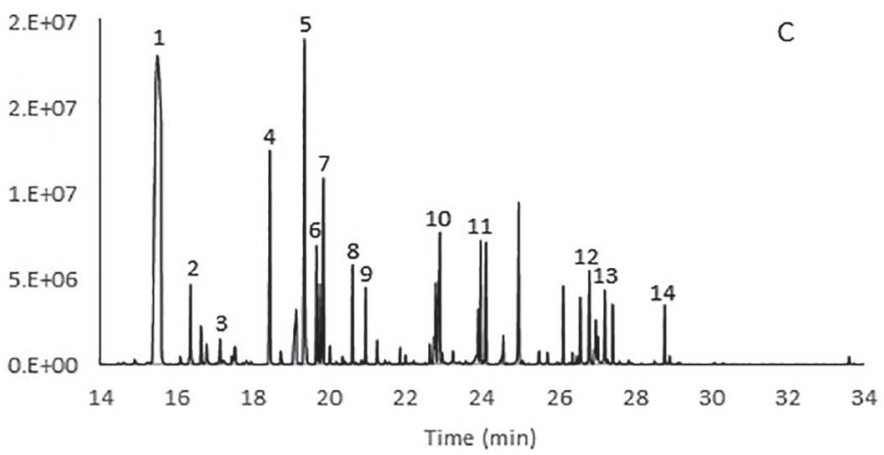

RC 180

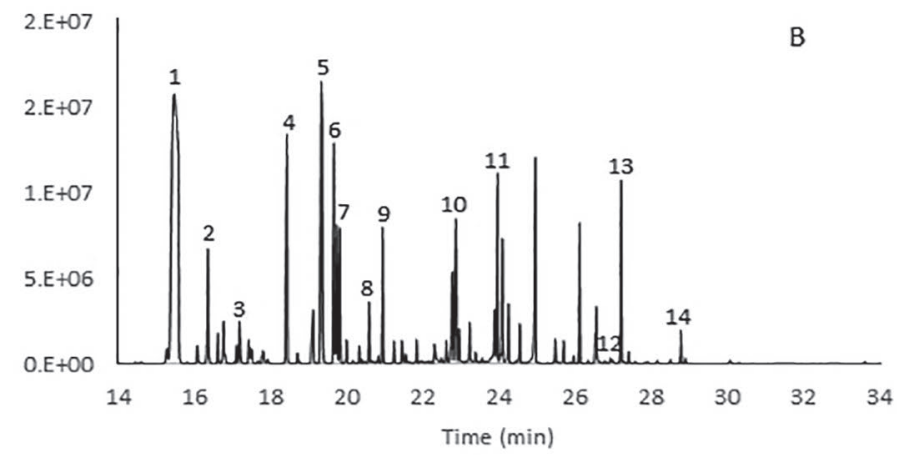

HC 180

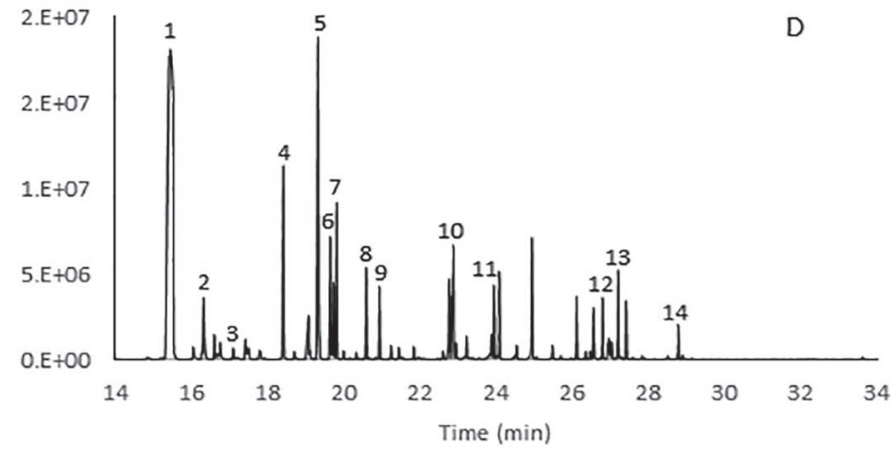

Figure 2. Gas chromatography-mass spectrometry representative chromatograms of cheese samples with significant peak identification: (A) raw milk cheese (RC) at $105 \mathrm{~d},(\mathrm{~B}) \mathrm{RC}$ at $180 \mathrm{~d}$, (C) heated milk cheese (HC) at $105 \mathrm{~d}$, and (D) HC at $180 \mathrm{~d}$ of ripening. 1 . Lactic acid, 2. alanine, 3. 3 -lactic acid, 4. phosphate, 5. leucine, 6. isoleucine, 7. proline, 8. serine, 9. threonine, 10. pyroglutamic acid, 11. glutamic acid, 12. lysine, 13. galactose, 14. myo-inositol.

tentially formed from the oxidation of glucose. We also found that the serine was a metabolite upregulated in HC samples. It is well known that milk heat treatments cause the denaturation of whey proteins determining an increase of serine, serine phosphate, glycosylated serine, and cysteine residues (Durazzo, 2017). Interestingly, level of fucose, a deoxyhexose metabolite, was found to be higher in cheeses obtained from thermized milk than those from raw milk. Moreover, we found higher levels of myo-inositol, a sugar-like carbohydrate, in cheeses obtained from thermized milk. Other upregulated discriminants, not detected in milk, were not annotated metabolites (unknowns) that shared a common fragmentation pattern ascribable to mono- or disaccharides (Table 5). The presence of different saccharides among the upregulated metabolites in $\mathrm{HC}$ samples leads us to hypothesize a lower consumption of these molecular components by microorganisms, the presence of which was depleted in the original milk by the heat treatment. The most downregulated metabolite in cheese obtained from thermized milk was $\alpha$-hydroxybutyric acid. In semi-hard-type and hard-type cheeses, hydroxy acids are considered as neither flavor compounds nor flavor precursor compounds and originate from the conversion of caseins to small peptides and AA (Smit et al., 2000). The latter are primarily needed by LAB for protein synthesis and are enzymatically transformed intracellularly by aminotransferases to $\alpha$-keto acids and then to hydroxy acids, CoA-esters, and aldehydes by dehydrogenase and decarboxylase enzymes. The increased AA conversions and the production of $\alpha$-hydroxy acids, $\alpha$-keto acids, and carboxylic acids production was confirmed for different cheeses by Yvon et al. (1998) and Banks et al. (2001) after adding $\alpha$-ketoglutarate to the curd. The pathways that lead to the formation of hydroxyl acids from the corresponding $\alpha$-ketoacids reduce the levels of $\alpha$-ketoacids to produce volatile cheese flavors.

In our experimental conditions, the milk thermization process determined a lower level of $\alpha$-hydroxybutyric acid and this fact is probably related to lower dehydrogenase enzyme activity of LAB when compared with raw milk. Interestingly, $\alpha$-ketoglutarate can be also produced by a glutamate dehydrogenase rather than transamination, thus lower levels of glutamic acid found in thermized milk and cheese obtained from 
Table 5. GC-MS metabolite characteristics

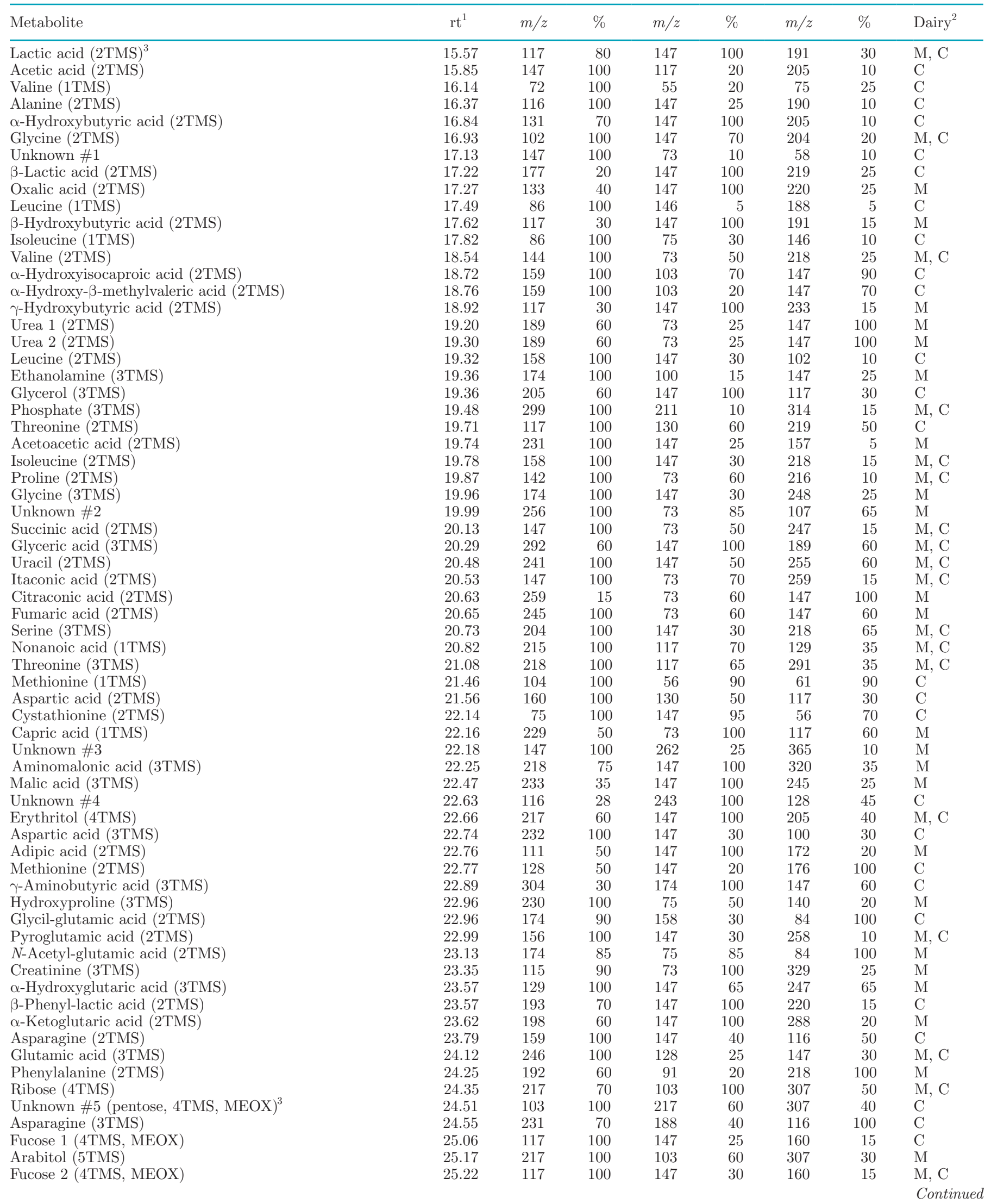


Table 5 (Continued). GC-MS metabolite characteristics

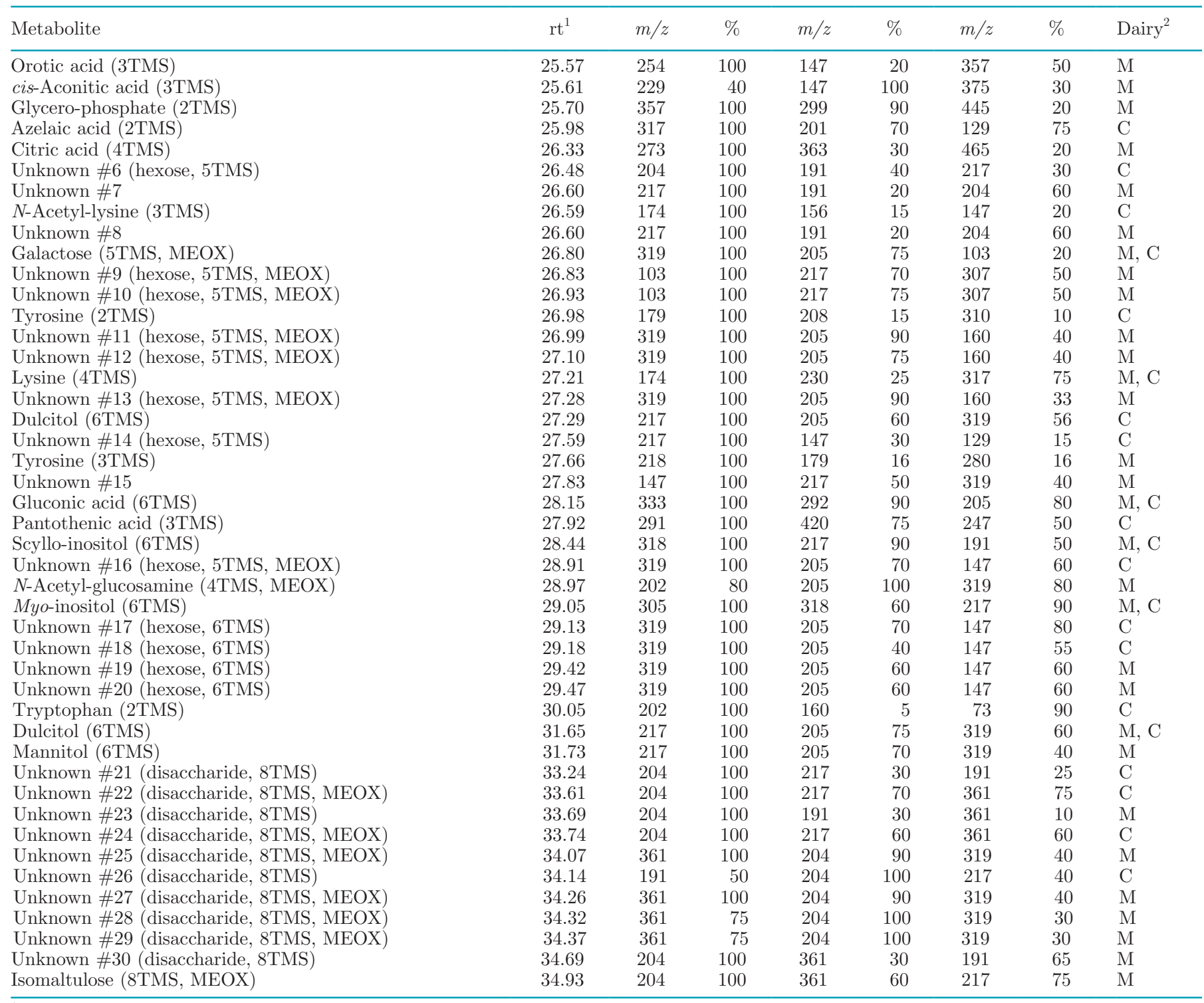

${ }^{1} \mathrm{rt}=$ retention time $(\mathrm{min})$.

${ }^{2}$ Class of samples ( $\mathrm{M}=$ milk, $\mathrm{C}=$ cheese) where metabolites were found.

${ }^{3} \mathrm{TMS}=$ trimethylsilyl derivate; MEOX $=$ methyloxime derivate

thermized milk may be also tightly correlated with a dramatically reduced enzymatic activity. On the other hand, pyroglutamic acid can be easily produced by thermophilic LAB as demonstrated by Mucchetti et al. (2002) and its levels should increase with the hard-type cheese ripening process. Considering that aspartic acid can be produced or consumed by LAB aminotransferases (Dudley and Steele, 2001) whereas asparagine is produced from aspartic acid through asparagine synthetase (Weimer, 2007), low levels of these $2 \mathrm{AA}$ in cheese are a signature of reduced $\mathrm{AA}$ catabolism and consequently of a reduction in aroma compounds. Furthermore, we noted that 2 metabolites (i.e., $\alpha$-ketoglutaric acid and $\alpha$-hydroxyglutaric acid) were found only in milk samples. Same conclusions can be drawn for proline and lysine that are biosynthetically produced by arginine and glutamate metabolism and are catabolized in cheese to fatty acids (Dudley and Steele, 2001). Lyases are responsible for the conversion of AA. In cheese obtained from thermized milk we found lower levels of threonine, another flavor compound, and this fact can be related to the activity of threonine aldolase responsible to produce acetaldehyde and eventually ethanol (not detectable with our ana- 
Table 6. Orthogonal least squares-discriminant analysis variable importance in projection (VIP) values of metabolites discriminant between heated milk cheese (HC) and raw milk cheese (RC) samples (model 1 in Table S2; https://doi.org/10.3168/jds.2018-15885)

\begin{tabular}{|c|c|c|c|c|c|}
\hline Upregulated in $\mathrm{HC}$ & VIP & $\mathrm{SE}$ in $\mathrm{cv}^{1}$ & Downregulated in $\mathrm{HC}$ & VIP & $\mathrm{SE}$ in $\mathrm{cv}$ \\
\hline Galactose & 1.67 & 0.21 & $\alpha$-Hydroxybutyric acid & 1.55 & 0.38 \\
\hline Gluconic acid & 1.56 & 0.53 & Lysine & 1.52 & 0.40 \\
\hline Fucose & 1.49 & 0.47 & Uracil & 1.51 & 0.55 \\
\hline Serine & 1.44 & 0.70 & Isoleucine & 1.24 & 0.60 \\
\hline Unknown 11 & 1.38 & 0.48 & $\beta$-Lactic acid & 1.23 & 0.50 \\
\hline Unknown 8 & 1.36 & 0.83 & Glutamic acid & 1.18 & 0.25 \\
\hline Unknown 12 & 1.34 & 0.57 & Pyroglutamic acid & 1.16 & 0.36 \\
\hline Unknown 10 & 1.23 & 0.65 & Threonine & 1.11 & 0.66 \\
\hline Myo-inositol & 1.22 & 0.21 & Aspartic acid & 1.09 & 0.26 \\
\hline Lactic acid & 1.07 & 0.58 & Proline & 1.01 & 0.64 \\
\hline Ribose & 1.01 & 0.67 & Asparagine & 1.00 & 0.37 \\
\hline Unknown 9 & 1.01 & 0.55 & & & \\
\hline
\end{tabular}

${ }^{1}$ Standard errors in cross validation.

lytical platform; Marshall and Cole, 1983). Uracil can be formed as a consequence of the enzymatic hydrolysis of uridine by LAB and nonstarter LAB microorganisms and lower levels of this metabolite found in thermized milk and cheese can be attributed to their lower enzymatic activity. Moreover, the strong correlations among $\mathrm{AA}$ and their concomitant downregulation in $\mathrm{HC}$ lead us to hypothesize an overall weaker proteolytic activity in $\mathrm{HC}$ when compared with $\mathrm{RC}$, as found analyzing the proteolytic indices reported in Tables 1 and 2 .

The effects of thermization on the ripening periods (i.e., 105 and 180 d) were also tested by OPLS-DA (i.e., models 2 and 3 reported in Supplemental Table S2; https://doi.org/10.3168/jds.2018-15885). The good performance of the statistical analysis indicates that $\mathrm{HC}$ samples were distinguishable from RC samples at both 105 and $180 \mathrm{~d}$ of ripening. The effects of ripening on the metabolite profile were also tested, comparing samples collected at $105 \mathrm{~d}$ of ripening with those at 180 d. The OPLS-DA results showed a good classification power (see model 4 in Supplemental Table S2; https: //doi.org/10.3168/jds.2018-15885). Cheese samples at $180 \mathrm{~d}$ with respect to samples at $105 \mathrm{~d}$, in accordance with a major proteolysis extent during ripening, showed

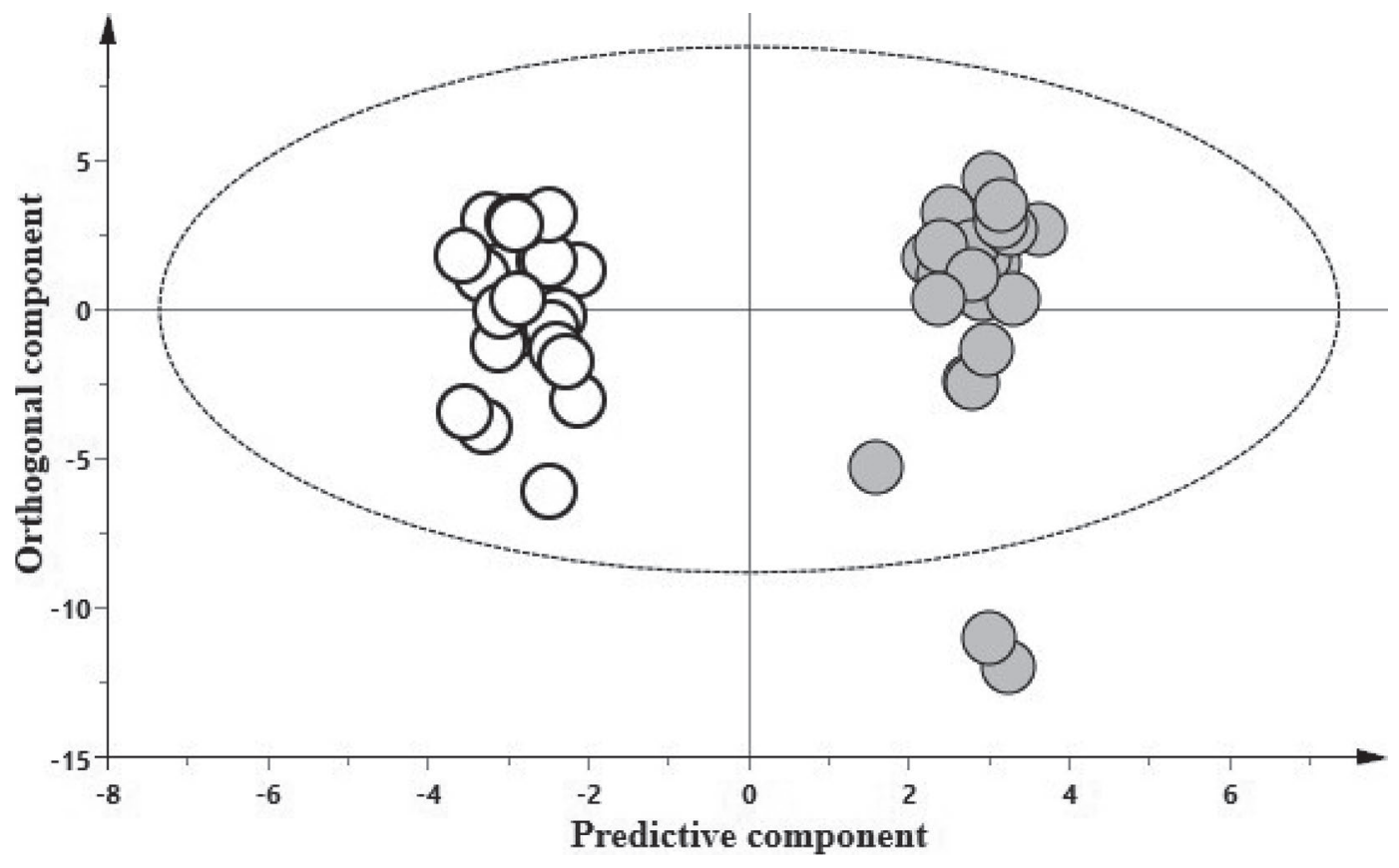

Figure 3. Orthogonal least squares-discriminant analysis score plot of GC-MS data of raw milk cheese (RC) versus heated milk cheese (HC) samples (model 1 in Table S2; https://doi.org/10.3168/jds.2018-15885). Empty circles represent RC samples, and filled circles represent HC samples. 
higher levels of methionine, isoleucine, valine, and other free AA (Supplemental Table S3; https://doi.org/10 $.3168 /$ jds.2018-15885). Moreover, in 180-d cheese, we found lower levels of inorganic phosphate, which was negatively correlated $(\mathrm{r}=-0.89)$ with protein levels known to increase during cheese ripening.

However, comparing results of Supplemental Table S2 (https://doi.org/10.3168/jds.2018-15885) and the quality of OPLS-DA models, we can state that thermization had a stronger effect on the polar fraction metabolite profile than the ripening stage.

\section{CONCLUSIONS}

In summary, for the samples studied herein, the effects of milk thermization on cheese macro-compositional parameters, proteolysis indices, and FFA levels were minimal compared with the predominant effects of milk seasonality and cheese ripening stage. On the contrary, the GC-MS polar metabolite profile analyzed by a multivariate statistical approach, considering the correlations among variables, highlighted all the concomitant changes of the metabolites due to milk thermization, thus giving a broader picture of biomarker candidates and a more robust classification. The application of the proposed GC-MS multivariate analytical protocol may have potential application to protect PDO high-quality ovine cheeses, such as Fiore Sardo, Roquefort, Idiazabal, and Roncal from the fraudulent use of thermized milk.

\section{ACKNOWLEDGMENTS}

This work was supported by Regione Autonoma della Sardegna, Italy (Legge Regionale n. 15 del 17.11.2010).

\section{REFERENCES}

Addis, M., G. Piredda, M. Pes, R. Di Salvo, M. F. Scintu, and A. Pirisi. 2005. Effect of the use of three different lamb paste rennets on lipolysis of the PDO Pecorino Romano Cheese. Int. Dairy J. 15:563-569.

Afshari, R., C. J. Pillidge, D. A. Dias, A. M. Osborn, and H. Gill. 2018. Cheesomics: The future pathway to understanding cheese flavour and quality. Crit. Rev. Food Sci. Nutr. https://doi.org/10 .1080/10408398.2018.1512471.

Banks, J. M., M. Yvon, J. C. Gripon, A. Miguel, E. Y. Brechany, A. G. Williams, and D. D. Muir. 2001. Enhancement of amino acid catabolism in Cheddar cheese using $\alpha$-ketoglutarate: Amino acid degradation in relation to volatile compounds and aroma character. Int. Dairy J. 11:235-243.

Caboni, P., A. Murgia, A. Porcu, M. Demuru, G. Pulina, and A. Nudda. 2016. Gas chromatography-mass spectrometry metabolomics of goat milk with different polymorphism at the $\alpha_{\mathrm{S1}}$-casein genotype locus. J. Dairy Sci. 99:6046-6051. https://doi.org/10.3168/ jds.2015-10537.
Carta, A., S. R. Sanna, and S. Casu. 1995. Estimating lactation curves and seasonal effects for milk, fat and protein in Sarda dairy sheep with a test day model. Livest. Prod. Sci. 44:37-44.

Collins, Y. F., P. L. McSweeney, and M. G. Wilkinson. 2003. Lipolysis and free fatty acid catabolism in cheese: A review of current knowledge. Int. Dairy J. 13:841-866.

Driessen, F. M. 1989. Heat-induced changes in milk. Bull. Int. Dairy Fed. 238:71-93.

Dudley, E., and J. L. Steele. 2001. Lactococcus lactis LM0230 contains a single aminotransferase involved in aspartate biosynthesis, which is essential for growth in milk. Microbiology 147:215-224.

Durazzo, A. 2017. Milk: Bioactive components and role in human nutrition. Beverages 3:63. https://doi.org/10.3390/beverages3040063.

EC. 2004. Council regulation 853/2004. Off. J. Eur. Communities 139:55.

EEC. 1992. Council directive 92/46. Off. J. Eur. Communities 268:1.

Eriksson, L., E. Johansson, N. Kettaneh-Wold, J. Trygg, C. Wikström, and S. Wold. 2006. Multi-and megavariate data analysis part I: Basic principles and applications. Umetrics, Umea, Sweden.

Farkye, N. Y., and G. I. Imafidon. 1995. Thermal denaturation of indigenous milk enzymes. Pages 331-348 in Heat-Induced Changes In Milk - Special issue 9501. Int. Dairy Fed., Brussels, Belgium.

Gathercole, J., M. G. Reis, M. Agnew, M. M. Reis, R. Humphrey, P. Harris, S. Clerens, B. Haigh, and J. M. Dyer. 2017. Molecular modification associated with the heat treatment of bovine milk. Int. Dairy J. 73:74-83.

Gaya, P., C. Sánchez, M. Nuñez, and E. Fernández-García. 2005. Proteolysis during ripening of Manchego cheese made from raw or pasteurized ewes' milk. Seasonal variation. J. Dairy Res. 72:287-295.

Gowda, G. N., and D. Djukovic. 2014. Overview of Mass Spectrometry-Based Metabolomics: Opportunities and Challenges. Pages 3-12 in Mass Spectrometry in Metabolomics. Humana Press, New York, NY.

Gripon, J. C., M. J. Desmazeaud, D. Le Bars, and J. L. Bergere. 1975. Etude du rôle des micro-organismes et des enzymes au cours de la maturation des fromages. II.-Influence de la présure commerciale. Lait 55:502-516.

Ha, J. K., and R. C. Lindsay. 1993. Release of volatile branched-chain and other fatty acids from ruminant milk fats by various lipases. J. Dairy Sci. 76:677-690.

Hilton, D. C., and M. J. Lewis. 2017. High Temperature Processing of Milk and Milk Products. Wiley, Chichester, Oxford, UK. https:// doi.org/10.1002/9781118460467.

ISO. (International Organization for Standardization). 2004. Cheese and processed cheese-Determination of the total solids content. Method number 5534:2004 (IDF 4:2004). ISO, Geneva, Switzerland.

ISO. (International Organization for Standardization). 2006. Cheese and processed cheese products - Determination of chloride content-Potentiometric titration method. Method number 5963:2006 (IDF 88:2006). ISO, Geneva, Switzerland.

ISO. (International Organization for Standardization). 2010. Milk, cream and evaporated milk-Determination of total solids content. Method number 6731:2010 (IDF 21:2010). ISO, Geneva, Switzerland.

ISO. (International Organization for Standardization). 2014. Milk and milk products - Determination of nitrogen content-Part 1: Kjeldahl principle and crude protein calculation. Method number 8968-1:2014 (IDF 20-1:2014). ISO, Geneva, Switzerland.

Lyster, R. L. J., and R. Aschaffenburg. 1962. The reactivation of milk alkaline phosphatase after heat treatment. J. Dairy Res. 29:21-35.

Marshall, V. M., and W. M. Cole. 1983. Threonine aldolase and alcohol dehydrogenase activities in Lactobacillus bulgaricus and Lactobacillus acidophilus and their contribution to flavour production in fermented milks. J. Dairy Res. 50:375-379.

Mucchetti, G., F. Locci, P. Massara, R. Vitale, and E. Neviani. 2002. Production of pyroglutamic acid by thermophilic lactic acid bacteria in hard-cooked mini-cheeses. J. Dairy Sci. 85:2489-2496.

Mulas, G., T. Roggio, S. Uzzau, and R. Anedda. 2013. A new magnetic resonance imaging approach for discriminating Sardinian 
sheep milk cheese made from heat-treated or raw milk. J. Dairy Sci. 96:7393-7403.

Murthy, G. K., S. Cox, and L. Taylor. 1976. Reactivation of alkaline phosphatase in ultra-high-temperature, short-time processed liquid milk products. J. Dairy Sci. 59:1699-1710.

Olano, A., and M. M. Calvo. 1989. Kinetics of lactulose, galactose and epilactose formation during heat-treatment of milk. Food Chem. 34:239-248.

Piga, C., P. P. Urgeghe, G. Piredda, M. F. Scintu, R. Di Salvo, and G. Sanna. 2013. Thermal inactivation and variability of $\gamma$-glutamyltranferase and $\alpha$-L-fucosidase enzymatic activity in sheep milk. Lebensm. Wiss. Technol. 54:1521-1556.

Pinna, G., A. Pirisi, G. Piredda, M. Addis, and R. Di Salvo. 1999. Effetto della termizzazione del latte sul formaggio DOP Fiore Sardo: 2. Andamento della Lipolisi nel Corso della Maturazione. Sci. Tec. Latt.-Casearia 50:366-377.

Pirisi, A., G. Pinna, and C. M. Papoff. 1999. Effetto della termizzazione del latte sul formaggio DOP Fiore Sardo: 1. Caratteristiche Fisico-Chimiche. Sci. Tec. Latt.-Casearia 50:353-366.

Pisano, M. B., P. Scano, A. Murgia, S. Cosentino, and P. Caboni. 2016. Metabolomics and microbiological profile of Italian mozzarella cheese produced with buffalo and cow milk. Food Chem. 192:618-624. https://doi.org/10.1016/j.foodchem.2015.07.061.

Rankin, S. A., A. Christiansen, W. Lee, D. S. Banavara, and A. LopezHernandez. 2010. A Invited review: The application of alkaline phosphatase assays for the validation of milk product pasteurization. J. Dairy Sci. 93:5538-5551. https://doi.org/10.3168/jds.2010 $-3400$

Raynal-Ljutovac, K., Y. W. Park, F. Gaucheron, and S. Bouhallab. 2007. Heat stability and enzymatic modifications of goat and sheep milk. Small Rumin. Res. 68:207-220.

Santiago-López, L., J. E. Aguilar-Toalá, A. Hernández-Mendoza, B. Vallejo-Cordoba, A. M. Liceaga, and A. F. González-Córdova.
2018. Invited review: Bioactive compounds produced during cheese ripening and health effects associated with aged cheese consumption. J. Dairy Sci. 101:3742-3757.

Scano, P., A. Murgia, F. M. Pirisi, and P. Caboni. 2014. A gas chromatography-mass spectrometry-based metabolomic approach for the characterization of goat milk compared with cow milk. J. Dairy Sci. 97:6057-6066. https://doi.org/10.3168/jds.2014-8247.

Scintu, M. F., E. Daga, and A. Ledda. 2000. Evaluation of spectrophotometric and fluorometric methods for alkaline phosphatase activity determination in ewe's milk. J. Food Prot. 63:1258-1261.

Smit, G.. A. Verheul, R. Van Kranenburg, E. Ayad, R. Siezen, and W. Engels. 2000. Cheese flavour development by enzymatic conversions of peptides and amino acids. Food Res. Int. 33:153-160.

Sousa, M. J., and F. X. Malcata. 1997. Ripening of ovine milk cheeses: Effect of plant rennet, pasteurization and addition of starter on lipolysis. Food Chem. 59:427-432.

Soxhlet, F. 1879. Die gewichtsanalytische Bestimmung des Milchfettes. Dingler's Polyt. J. 232:461-465.

Troyano, E., M. Villamiel, A. Olano, J. Sanz, and I. Martinez-Castro. 1996. Monosaccharides and myo-inositol in commercial milks. J. Agric. Food Chem. 44:815-817.

Vélez, M. A., M. C. Perotti, I. V. Wolf, E. R. Hynes, and C. A. Zalazar. 2010. Influence of milk pretreatment on production of free fatty acids and volatile compounds in hard cheeses: Heat treatment and mechanical agitation. J. Dairy Sci. 93:4545-4554.

Weimer, B. C., ed. 2007. Improving the Flavour of Cheese. Elsevier, Amsterdam, the Netherlands.

Yvon, M., S. Berthelot, and J. C. Gripon. 1998. Adding $\alpha$-ketoglutarate to semi-hard cheese curd highly enhances the conversion of amino acids to aroma compounds. Int. Dairy J. 8:889-898. 